
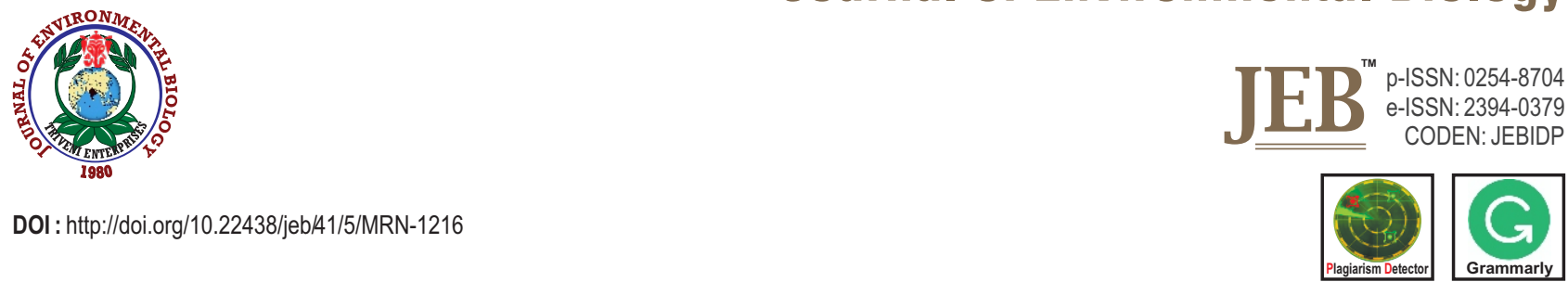

\title{
Survey based economic evaluation of ecosystem services of mangrove from Uttar Kannada district of Karnataka, India
}

\author{
S.M. Sachin', V.K. Yadav", S. Pal', S. Karmakar ${ }^{3}$ and V.S. Bharti ${ }^{2}$ \\ ${ }^{1}$ Fisheries Economics, Extension and Statistics Division, ICAR- Central Institute of Fisheries Education, Mumbai - 400061 , India \\ ${ }^{2}$ Aquatic Environments and Health Management Division, ICAR- Central Institute of Fisheries Education, Mumbai - 400061 , India \\ ${ }^{3}$ Department of Aquatic Environment Management, West Bengal University of Animal and Fishery sciences, Kolkata - 700 094, India \\ *Corresponding Author Email : vinodkumar@cife.edu.in
}

\section{Abstract}

Aim: The study was aimed to assess, in monetary units the services gained from the mangrove ecosystem of Uttara Kannada district of Karnataka, India and to analyse the people's perception about the importance of mangroves besides their willingness to pay (WTP) for its conservation.

Methodology: Study was conducted with double-bounded dichotomous approach and poll questions were asked to the respondents. A binary logistic regression model was applied to analyse the Willingness to Pay of the respondents to develop and maintain the mangroves.

Results: Respondents of the areas were less aware about the ecosystem services such as carbon sequestration which are not directly influencing them. They are highly dependent on the mangrove resources and gaining several benefit which are significant in monetary units. Among the respondents, inland fishers are willing to pay more for mangrove development and maintenance compared to marine fishermen and Gazni farmers. The WTP is further influenced by the socio-economic parameters such as age, income level, educational status etc.

Interpretation: Development and management of mangrove ecosystem could lead to increased ecosystem services, which in term will be implicated on the overall improvement of the socioeconomic standards of the dependent communities.

Keywords: Economic evaluation, Mangroves ecosystem, Uttar Kannada, Willingness to Pay

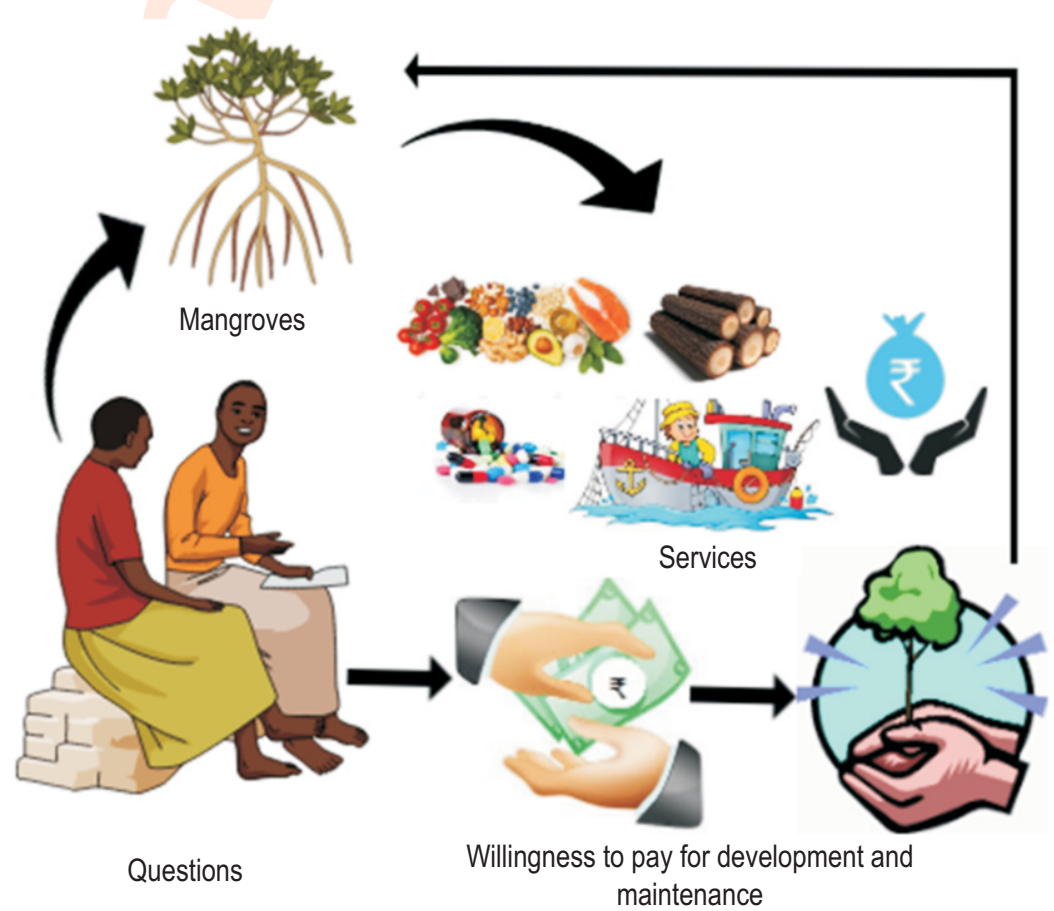

How to cite : Sachin, S.M., V.K. Yadav, S. Pal, S. Karmakar and V.S. Bharti: Survey based economic evaluation of ecosystem services of mangrove from Uttar Kannada district of Karnataka, India. J. Environ. Biol., 41, 980-986 (2020). 


\section{Introduction}

Mangroves are shrubs or small tropical trees that occur in the coastal intertidal zones of tropics and subtropics (Chandran et al., 2012). Mangroves are one of the most productive ecosystems on earth and considered as a renewable resources (Kathiresan, 2010). A survey of the existing global mangroves indicate a total cover of about 18 million ha, inhabiting in 118 countries and territories in the tropical and subtropical regions (Spalding, 1997). In south and southeast Asian countries, mangroves are more diverse comprising about $42 \%$ of the world mangrove area. Indian mangrove cover comprises about $3.3 \%$ of the global mangroves. It covers $60 \%$ is on the east coast, $27 \%$ on the west coasts and $13 \%$ in Andaman \& Nicobar Islands, covering an area of about 4921 sq km (Singh et al., 2012; Gol, 2017).

Mangrove ecosystem supply a groups of essential services that support human welfare, including provisioning services (e.g., fish, timber, fuel-wood etc.), regulating services (e.g., flood, storm and erosion control, climate resilience, prevention of saltwater intrusion etc.), supporting services (e.g., breeding, spawning and nursery habitat for commercial fish species, nutrient cycling, rich biodiversity etc.) and cultural services (e.g., recreation, aesthetic and non-use benefits) (UNEP, 2007; TEEB, 2010). The term Ecosystem Services (ES) is widely recognised as a way to frame society's dependence on the planet's ecosystems. United Nations Millennium Ecosystem Assessment (MA, 2005) and the Economics of Ecosystems and Biodiversity (TEEB, 2010) have concluded that ES are highly valuable to the human society. Despite the increasing awareness, many of the world's ES remain underestimated or not correctly recognised and hence less attention is being paid for proper ecosystem assessment and their management.

An economic evaluation of ES is a tool to measure and compare the services derived from an ecosystem while ensuring the responsible exploitation and management of the resources. To stimulate public awareness and policy action, several studies on mangrove ecosystem for assessment of ES (both coastal and terrestrial) at both macro and micro level, has been conducted in recent years (Kumar et al., 2016). But, there is less comprehension on the importance of these goods and raw materials concerning their multiplier effects at local and national levels and national economy besides their role in local livelihoods and poverty alleviation. Hence, there is a gap of dependable information based on systematic and scientific studies. Furthermore, a comprehensive valuation of such a unique ecosystem is highly trusted for reliable, unbiased conservation and management policies and their effective implementations. Most valuation studies were done in developed nations, and inconceivably unique in relation to the event and expenses assessed in developed nations which are particularly dissimilar from the same in India, where mangroves assume a notable part in the life and vocation of the coastal population (Debroy et al., 2012).
Karnataka has a highly populated coastal zone with a mangrove cover of about $8 \mathrm{sq}$. km, while the importance of such resource is largely overlooked (Debroy et al., 2012; Gol, 2017). The coastal areas of Uttara Kannada district of Karnataka, India experienced rapid economic development and high population pressure, which may potentially threaten the mangrove forest of the area. The current study was aimed to estimate, in monetary units the services obtained from the mangrove ecosystem of the area and to analyse the people's perception about the importance of mangroves and their willingness to pay for its conservation and maintenance.

\section{Materials and Methods}

Study area : The study was conducted in mangroves of Aghanashini Estuary of Uttara Kannada District, Karnataka. The general population in these zones to a great extent relies on the Mangrove biological community for rural living.

Sampling framework: The study covered over 200 respondents from ten villages with different stakeholders and was categorised into three groups, i.e. inland fishers, marine fishers and Gazni farmers. Among them 99 (49.5\%) were inland fishermen, 31 $(15.5 \%)$ were marine fishermen, and 70 (35\%) were Gazni farmers.

Methodology : The survey was started with the collection of the background information about the respondents including socioeconomic characteristics like age, gender, education, marital status, occupation, income, etc. to know farmers standard of living in the study area. Further, the respondents were explained about threat factors and asked for farmers/fishers Willingness to Pay (WTP) for the development, conservation and regular maintenance of mangroves and about some mangrove associated information. The method used in the study may be referred as a referendum followed by the double-bounded dichotomous approach. A poll question was posed by asking respondents if they are willing to pay for the proposed policy (yes or no). When the respondents answered 'no', then they were invited to give their reasons for not being WTP for the development and maintenance of the mangroves. If the respondents answered 'yes', they were further asked with dichotomous choice WTP questions.

The Contingent Valuation (CV) method was used in the study, which estimates an individual's WTP for the goods by developing a hypothetical market (Kostald, 2000). CV is a method to state their choices or willingness to contribute from direct enquires. WTP reflects the ability of people for the preference for environmental quality, and it is generally influenced by several factors, including an individual's income, gender, cultural preferences, education, or age (Tri and Vietnam, 2007). The estimation of the value of the natural system as consideration of option and existence value is usually defined regarding the 
preservation of species, groups of species or ecosystems (Randall, 1991, Bishop, 1978). The willingness to pay (WTP) was the dependent variable, and the explanatory variables include that variable which directly or indirectly affects the willingness to pay of the stakeholder. The explanatory variables were categorised into three types, viz., quantitative variables, binary variables and categorical variables. The quantitative variables comprises of age, household income, distance to the water body and time spent on the collection of resources. The variable bid value represents the amount in rupees that the respondents are willing to pay. The binary variables included gender, education, and marital status. One categorical variable namely occupation was also included as an explanatory variable having three levels to see the response of the stated WTP across various occupational strata.

Logit model equation : A binary logistic regression model (Logit Model) were developed between the WTP ("yes" or "no") and with five independent variables (continuous and categorical): age, gender, income, education and occupation .The probability of saying "yes" or "no" of WTP has been written as follows:

$$
p=\frac{1}{1+e^{-z}}
$$

where, $z=\beta_{0}+\beta_{1} x_{1}+\beta_{2} x_{2}+\beta_{3} x_{3}+\beta_{4} x_{4}+\beta_{5} x_{5}$ in which $\beta_{0}$ and $\beta_{i}(i=1$ to $5)$ are the regression constants and $x_{i}(i=1$ to 5$)$ are above mentioned five independent variables

To assess the misclassification rate, we considered predicted $Y$ as 1 when $p$ e" 0.5 and 0 when $p<0.5$. The model was fitted using a maximum likelihood method (Yadav et al., 2016). Forward Wald step method was employed to select the significant variables in the final model. The $p$-value for statistical testing of variable significance for inclusion in and exclusion from the model was generally set to 0.05 .

\section{Results and Discussion}

Identified ecosystem services : As mangroves are falling under ecological sensitive areas and due to its restricted uses, it is difficult to identify the all direct provisioning services of mangroves. In order to reveal its importance, proxy use values of the alternate goods and services used by the sampled households were taken into consideration.

Fig. 1 (a) present the identified regulatory services of mangroves in the Aghanashini river belt. Table shows, respondents' awareness on mangrove services was highest for providing shelter to aquatic and terrestrial animals (89\%) next to protection against flood control (85\%). Mangrove services on breeding or nursery ground for fishes are found to be $68.5 \%$. The least awareness of mangrove services is on carbon sequestration $(1.5 \%)$ next to erosion control $(12 \%)$. It can be inferred that peoples are taking most of the benefits or services from mangroves but having less knowledge and awareness on some important services like carbon sequestration and soil erosion.

Fig. 1 (b) present the identified provisioning services of mangroves in Aghanashini estuary. Observed values show that $98 \%$ of the respondents rated that mangroves can be used as the best source of energy followed by fish diversity $97 \%$. It is found that $38.5 \%$ respondents agreed that mangrove logs could be used for the construction of boats and $34 \%$ voted on its medicinal uses. Surprisingly, only $2.5 \%$ of respondents voted on the use of mangrove for manure purpose. The result reveals the high level of dependency of the respondents on the mangrove resources which indicates the substantial financial support of mangrove to them.

Household expenses towards goods and services produced from alternate sources show that all the respondent groups are spending an average amount of Rs. 12000/yr with major spending on energy. Next, they are spending on boat building ranging from Rs. 1, 20,000 to 2,00,000 as one time amount. It is found that, on an average most of the household spending Rs. 3000 to Rs. 4000/yr on medicine. However, they are spending very less on drinking water ranging from Rs. 900 to Rs. 1500/yr. Overall results indicate that marine fishermen are spending the highest amount (Rs. 220252.4/yr) followed by inland fishermen (Rs. 138494.4/yr) and Gazni farmers (Rs. $18021.6 / \mathrm{yr}$ ) for all goods and services. Assumed share of mangroves for provisioning services, $30 \%$ share of mangroves has been taken based on the per-capita availability of mangroves for each household. Observed values show that mangrove share on provisioning services was Rs. 41548.32, Rs. 66075.72 and Rs. 5406.48 per household per year for inland fishermen, marine fishermen and Gazni farmers respectively.

As far as fishing ground is concerned, most of the fishermen are fishing in the river $(63.07 \%)$ which are mangrove prone areas. The second most common fishing ground is marine fishing $(23.85 \%)$, where they fish in the coastal area as well as in open sea. Some of the fishermen $(13.07 \%)$ are fishing in the estuarine areas and found to be productive next to river and sea.

Table 1 represents that, majorities of the inland fishermen are using gillnet and cast net which are used for collecting fishes like mullets (madle), mackerel (bangade), lady fish (nogla), cat fish (saade), sciaenids (baana) and some perches. Some of them use drag net for collecting crabs (hesadi), soles (leppe) and shrimps (shetli). Fisherwomen commonly use baskets to collect bivalves which is one of the major fishery of that region. Most of the sea fishermen are using purse seine, gill net and trawl net mainly to collect sardine, mackerel, seer fish and other bottomdwelling fishes. Fishing trips of the fishermen households shows that both the fishermen groups go for more fishing in summer and winter season compared to the rainy season. 


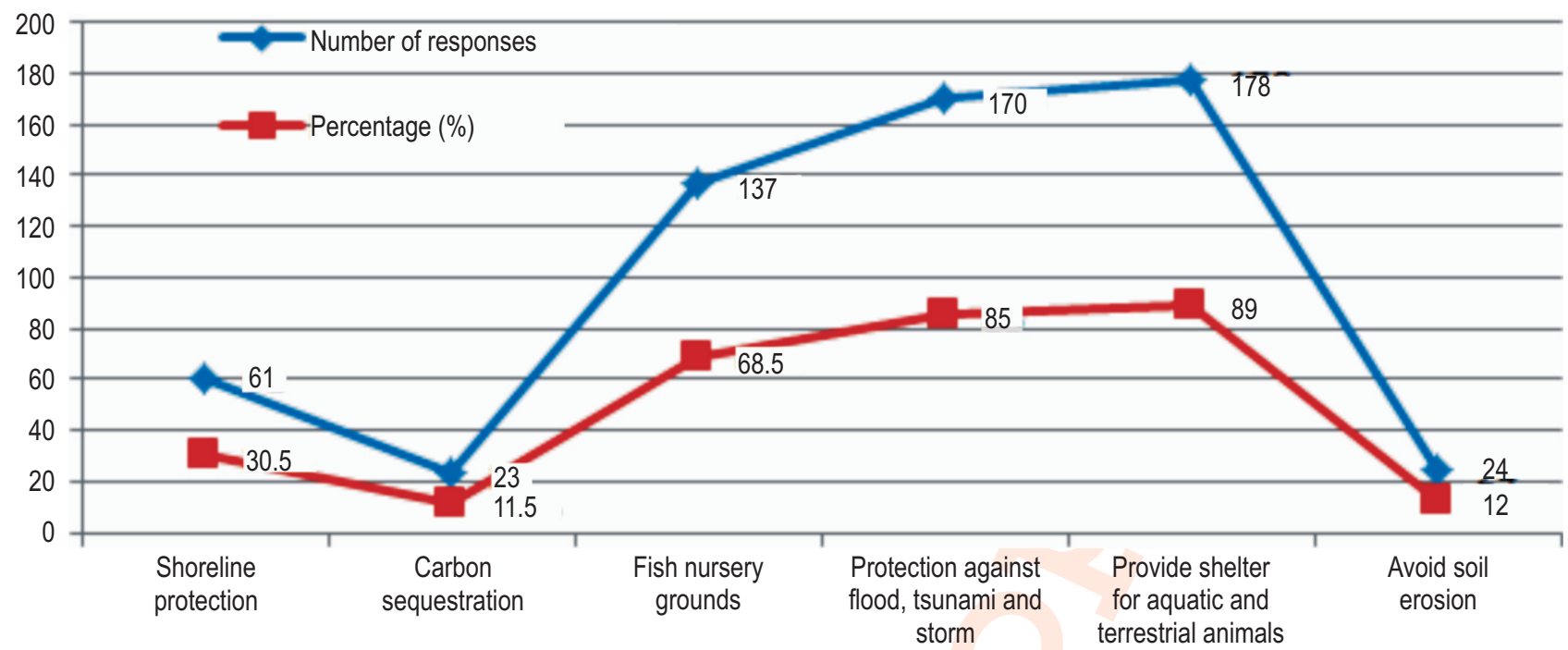

Regulatory services

Fig. 1(a) : Regulatory services by the mangroves.

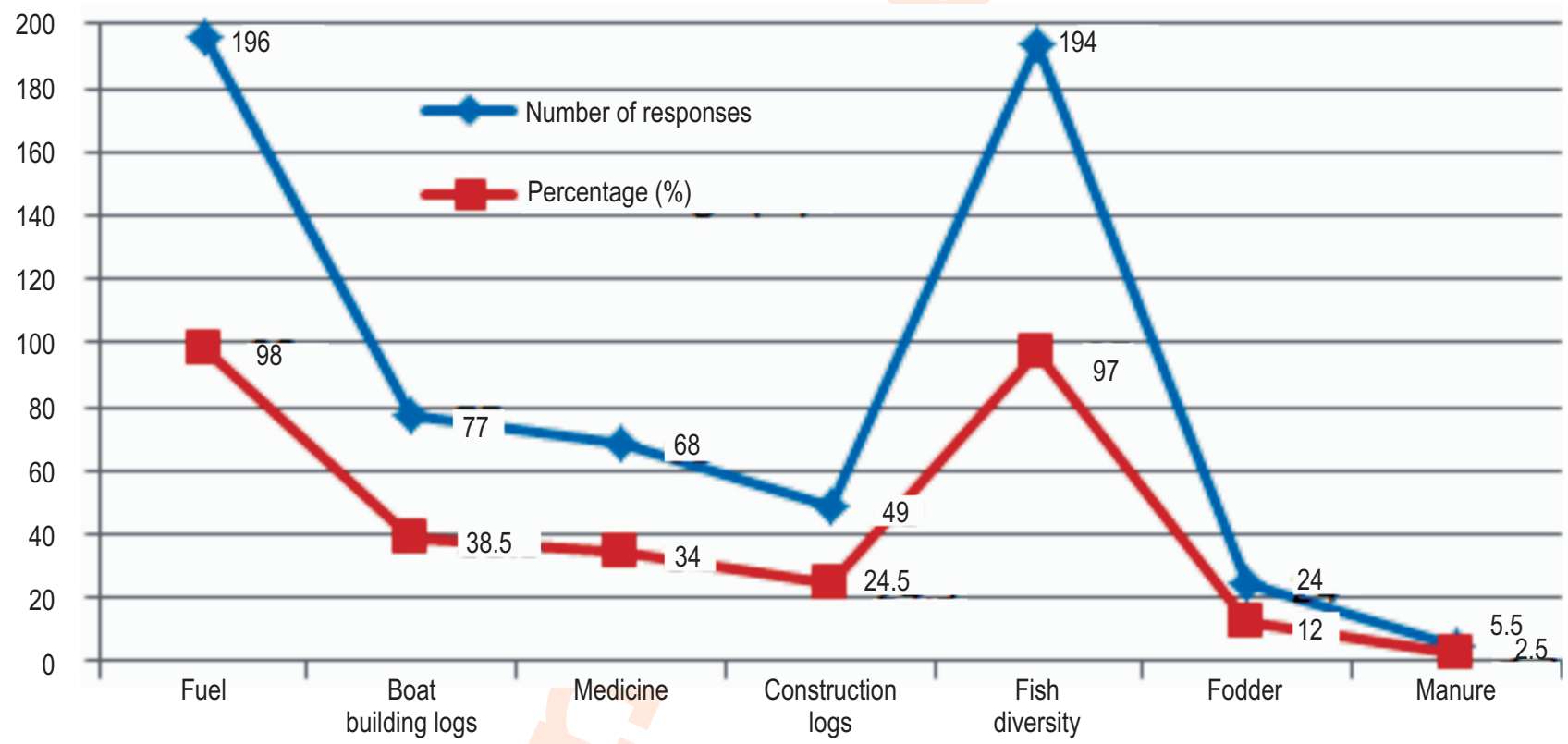

Provisioning services

Fig. 1(b) : Provisioning services from mangroves.

Marketed surplus of the fishermen household shows that both fishermen groups utilise an average quantity of fishes of about $1.30 \mathrm{~kg} /$ day out of total quantity harvested (average 6.14 $\mathrm{kg} /$ day) and they sell average quantity of $4.2 \mathrm{~kg} /$ day.

Most of the respondents (44\%) reveal that fishing operation is impaired by the mangroves including difficulties in net casting inside the mangrove areas due to its roots as well as branches. The second most perceived negative factor is mosquito menace $(39.5 \%)$ where they were irritated by mosquitos and lastly opined on water stagnation in the mangrove areas (27.5\%), which leads to the development of unpleasant smell or odour. Positive factors of mangroves perceived by sampled household shows that most of the fishermen are getting good fish catch (marine fishers $80.6 \%$ and inland fishers $83.8 \%$ ), good fish diversity (marine fishers $48.4 \%$ and inland fishers $69.7 \%$ ) near mangrove area. On other hands, Gazni farmers revealed that they got good rice yields (95.7\%) besides avoidance of soil erosion (34.3\%) by the mangroves. 
Table 1: Details on Nets used

\begin{tabular}{llll}
\hline Occupation & Nets & Frequency & Percentage (\%) \\
\hline Inland Fisherman & Cast net & 95 & 95.95 \\
& Drag net & 87 & 87.8 \\
& Gill net & 98 & 98.9 \\
Ring seine & 45 & 45.4 \\
& Bivalve baskets & 12 & 12.2 \\
Hooks & 9 & 9.9 \\
Marine fishermen & Purse seine & 20 & 64.51 \\
& Trawl net & 13 & 41.93 \\
& Gill net & 29 & 93.54 \\
& Castnet & 18 & 58.06 \\
& Hooks & 12 & 38.70 \\
\hline
\end{tabular}

Table 2: Willingness to pay

\begin{tabular}{lllll}
\hline W.T.P & $\begin{array}{l}\text { Size } \\
\text { (in numbers) }\end{array}$ & $\begin{array}{l}\text { Inland fishermen } \\
\text { (Rs in avg.) }\end{array}$ & $\begin{array}{l}\text { Marine fishermen } \\
\text { (Rs in avg.) }\end{array}$ & $\begin{array}{l}\text { Gazni farmers } \\
\text { (Rs in avg.) }\end{array}$ \\
\hline For development & 200 & 1151.51 & 1048.38 & 842.85 \\
For maintenance & 200 & 161.11 & 93.54 & 70 \\
\hline
\end{tabular}

avg.=Average, W.T.P=Willingness To Pay

Threat factors of mangroves perceived by sampled household reveal that sand mining (32\%) and cutting of mangroves for fodder (25.5\%) are major factors for the decline of mangroves. On the other hand, port development (16\%) and cutting of mangroves for aquaculture development $(21.5 \%)$ and firewood (12\%) may be the secondary reasons for the mangrove loss.

The perceived difference of fishing within and outside mangrove sampled households shows that the number of fish species, size and time spent for fishing in the mangrove area is much more preferable compared to non-mangrove areas. On the other hand, high-value fishes and fishing intensity of marine fishers is high in the non-mangrove area.

Table 2 represents the willingness to pay for the development and maintenance of the mangroves. The primary data on the willingness to pay for indirect economic benefits from mangroves for each of the three occupation groups were analyzed to estimate average monetary contribution towards both one-time investments for restoration and planting besides annual expenses towards the maintenance of mangroves. The results indicate that inland fishermen are willing to pay a higher amount (Average Rs. 1151.51) as a lifetime amount compares to marine fishermen (Average Rs. 1048.38) and Gazni farmers (Average Rs. 842.85). In terms of mangrove maintenance again the inland fishermen are willing to contribute more amount (Average Rs. 161.11) annually compared to sea fishermen (Average Rs. 93.54) and Gazni farmers (Average Rs. 70). The farmers and fisherman are willing to contribute an average Rs. 108 towards maintenance. The result is consistent with the findings of Sondak et al., 2019 where respondents are willing to pay an average IDR 18333.33 (Rs. 92.29) towards sustain the mangrove forest.

The results clearly indicate that those who are likely to be better benefitted from mangroves are willing to pay higher payment compared to those who are likely to be less connected with mangroves.

Table 3 represents the classification of WTP group for development of mangroves. Observed value shows that overall $83 \%$ of the respondents are correctly classified.

Table 4 represents the degree of WTP of saying 'yes' and 'no' for WTP- development. The result shows that, if we take illiterates as a reference point and move from illiterate to the primary, the likelihood of saying yes towards mangrove development is 1.575 times as compared to an illiterate person. If we move towards secondary education, the likelihood of saying yes towards development is 0.48 times. But, in case of above secondary education level likelihood of saying yes towards payment for mangrove development is 1.525 times compared to illiterates. The result is also consistent with the findings of Zaiton et al., 2019 where education assumed to have a strong positive correlation with their WTP for mangrove development.

Similarly, in case of income group if we take Rs. $>15000$ as a reference value and compared Rs. $<10,000$ and Rs. 10,000- 
Table 3 : Classification table under Logit model of WTP for mangrove development

\begin{tabular}{|c|c|c|c|c|c|}
\hline \multirow[t]{2}{*}{ Observed } & & \multicolumn{2}{|c|}{ Predicted WTP } & \multirow{2}{*}{\multicolumn{2}{|c|}{ Percentage $(\%)$ Correct }} \\
\hline & & 0 (NO) & 1 (YES) & & \\
\hline WTP_No & 0 & 2 & 31 & 6.10 & \\
\hline WTP_Yes & 1 & 3 & 164 & $\begin{array}{l}98.2 \\
\text { Overall \% }\end{array}$ & 83.0 \\
\hline
\end{tabular}

Table 4 : Logit model for degree of WTP for mangrove development

\begin{tabular}{lllll}
\hline Variables & Coefficients & Standard error & Wald & Exp(B) \\
\hline Education status & & & 2.659 & .289 \\
Education status(Primary) & .454 & .846 & .412 & 1.575 \\
Education status(Secondary) & -.727 & 1.133 & .237 & .483 \\
Educationstatus(Above Secondary) & .422 & .866 & 1.047 & 1.525 \\
Gender(Female) & -1.567 & 1.532 & 1.252 & .209 \\
Incomelevels & & & .329 & 1.860 \\
Incomelevels(Rs.<10,000/yr) & .620 & 1.082 & .865 & 2.751 \\
Incomelevels(Rs. 10,000-15000/yr) & 1.012 & 1.088 & .148 & .991 \\
Age & -.009 & .023 & 5.790 & 2.009 \\
Occupation & & & 1.058 & .549 \\
Occupation(Marine fishermen) & .698 & .678 & .807 & 1.032 \\
Occupation(Gaznifarmers) & -.599 & .667 & .000 & 1.351 \\
WTP_development & .032 & 2.200 & .023 & \\
Constant & .301 & 1.990 & & \\
\hline
\end{tabular}

15,000 income group WTP for development 1.86 and 2.75 times more respectively. As per Jumnongsong et al., 2015, monthly income was identified as an important factor for WTP for development of mangrove. The results for the age group shows that for a unit change in age the WTP of saying yes towards development is decreased by 0.999 times. In other words higher the age group lowers the WTP of saying yes for development.

Table 5 represents the classification of WTP group for mangrove maintenance. Observed value shows that overall $84 \%$ of the respondents are correctly classified towards maintenance.

Table 6 representing the significance of variables for mangrove maintenance. The result shows that, if we take illiterates as a reference point and move from illiterate to the primary, likelihood of saying yes towards maintenance is 2.113 times as compared to an illiterate person while for the secondary; likelihood of saying yes towards maintenance is 1.712 times. But, in case of above secondary, likelihood of saying yes towards payment for maintenance is 0.986 times compared to illiterates. In the case of income group if we take Rs. $>15000$ as a reference value and and compared Rs. < 10,000 and Rs. 10,000-15,000 income group WTP for maintenance is decreased by 0.369 and 0.477 times respectively as compared to the higher income group. As per Harini et al., 2019, income had significant effect on the willingness to manage mangrove forest; participants who have higher income levels would have higher WTP. The result is also consistent with the findings of Tuan et al., 2014 where income assumed to have a strong positive correlation with their WTP.

The results for age group shows that for a unit change in age the WTP of saying yes towards maintenance is decreased by 0.999 times in other words higher the age group lower the WTP of saying yes for maintenance. The result is also consistent with the findings of Suprapto et al., 2015 where for a unit change in age the WTP of saying yes towards maintenance is decreased by 0.722

The current study is exploratory research to understand the relationship between the conservation and development concerning mangroves and livelihoods of the coastal communities such as marine fishers, inland fishers and Gazni farmers in Uttara Kannada coast of Karnataka.

It can be concluded from the results that, those who have more stable incomes and higher educational levels could be targeted since they can work as key community actors for conducting mangrove restoration and protection activities. The study reveals that development in terms of increasing the income and employment opportunities could be achieved through the conservation of ecosystems. Hence, improvement of such an ecosystem could lead to increased ecosystem services, which in term will be implicated on the overall improvement of the socioeconomic standards of the dependent communities. 


\section{Acknowledgment}

This paper forms part of M. F. Sc dissertation of first author. Authors are thankful to the Director, ICAR-Central Institute of Fisheries Education, Mumbai for providing necessary supports and facilities to carry out the study.

\section{References}

Bishop, R.C.: Endangered species and uncertainty: The economics of a safe minimum standard. Am. J. Agric. Econ., 60, 10-18 (1978).

Chandran, S., T.V. Ramachandra, N.V. Joshi, P.N. Mesta, B. Settur and V.D. Mukri: Conservation and Management of Mangroves in Uttara Kannada, Central Western Ghat. Sahyadri Conservation Series 20, ENVIS Technical Report: 50 (2012).

Debroy, P., R. Jayaraman, M.N. Meeran and R.K. Ramkumar: Managing the mangroves economically: 'use it or lose it'. In: Meeting on Mangrove ecology, functioning and Management (MMM3), Galle, Sri Lanka, p. 54 (2012).

Gol: The state of forest report. Forest Survey of India, Ministry of Environment and Forests, Government of India, New Delhi (2017).

Harini, R., R.D. Ariani, W. Fistiningrum and D. Ariestantya: Economic valuation of mangrove management in kulon progo regency. International conference on environmental resources management in global region. IOP Conf. Series: Earth and Environmental Science 256, 012036 (2019).

Jumnongsong, S., W.G. Gallardo, K. Ikejima and R. Cochard: Factors affecting fishers' perceptions of benefits, threats, and state, and participation in mangrove management in Pak Phanang Bay, Thailand. J. Coast. Res., 31, 95-106 (2015).

Kathiresan, K.: Importance of Mangrove Forest in India. J. Coast. Env., 1, $11-26(2010)$.

Kostald, C.D.: Environmental Economics, Oxford University Press, Inc New York, U.S.A. (2000).

Kumar, K.K., L.R. Anneboina and R. Bhatta: Valuation of coastal and marine ecosystem services in India: Macro assessment. eSocial Sciences, Working Papers id:11440 (2016).

MA: Ecosystems and Human Well-being: Synthesis. Millennium
Ecosystem Assessment, Island Press, Washington D.C. (2005).

Randall, A.: The value of biodiversity. Ambio., 20, 64-68 (1991).

Singh, A.K., A. Ansari, D. Kumar and U.K. Sarkar: Status, biodiversity and distribution of mangroves in India: An overview. Uttar Pradesh State Biodiversity Board. Marine Biodiversity: One Ocean, Many Worlds of Life, pp. 59-67 (2012).

Sondak, C.F.A, E.Y. Kaligis and R.A. Bara: Economic valuation of Lansa Mangrove Forest, North Sulawesi Indonesia. Biodiversitas, 20, 978-986 (2019)

Spalding, M.D., E. Blasco and C.D. Field (Eds.): World Mangrove Atlas. The International Society for Mangrove Ecosystems, Okinawa, Japan. p. 178(1997).

Suprapto, D., M. Kirana, I. Susilowati and A. Fauzi: Economic valuation of mangrove restoration in indonesia. J. Ekon. Pemban., 16, 121-130 (2015)

TEEB: The Economics of Ecosystems and Biodiversity: Ecological and Economic Foundations (Ed.: P. Kumar). Earthscan, London and Washington D.C. (2010).

Tri, N.H. and V.N. Vietnam: The training course on sustainable management of mangrove ecosystems for the UNEP-GEF-South china sea project on reversing marine environmental degradation trends in the south china sea and the gulf of Thailand. UNEP/ USM29/4UNEP/4--9/5/2007, (2007).

Tuan, T.H., My, N. H.D., L.T.Q Anh and N.V. Toan: Using contingent valuation method to estimate the WTP for mangrove restoration under the context of climate change: A case study of Thi Nai lagoon, Quy Nhon city, Vietna. Oce. Coas. Manag., 95, 198-212 (2014)

UNEP: Mangroves of Western and Central Africa. UNEP Regional Seas Programme/UNEP-WCMC, United Nations Environment Program (2007).

Yadav, V.K., S. Jahageerdar, V. Ramasubramanian, V.S. Bharti and J. Adinarayana: Use of different approaches to model catch per unit effort (CPUE) abundance of fish. Ind. J. Mar. Sci., 45, 1677-1687 (2016).

Zaiton, S., M.M. Huda-Farhana and B.H. Basri: Conservation of mangroves in Kuala Perlis, Malaysia- A case study of socioeconomic attributes of fisherman driving valuation in sustaining livelihood through forest management. J. Trop. For. Sci., 31, 433$442(2019)$ 